\title{
A MULHER DOMADA: REPRESENTAÇÕES SOCIAIS DO PROTAGONISMO FEMININO EM PARADIDÁTICOS DOS SÉCULOS XVII E XIX ADOTADOS POR ESCOLAS DE TERESINA (PI) ${ }^{1}$
}

\author{
Ana Kelma Cunha Gallas ${ }^{2}$ \\ Samara Calassa de Albuquerque ${ }^{3}$ \\ Gabryelly Stephany da Silva Campelo ${ }^{4}$ \\ Centro Universitário Santo Agostinho - UNIFSA
}

\section{RESUMO}

Concebidos como "espaço de reflexão social e da própria condição do indivíduo", os paradidáticos são entendidos como artefatos dotados de uma significativa "função ideológica e cultural" (CHOPPIN, 2004), atuando na reprodução de modelos existenciais e normativos, elaborados a partir das lógicas que predominam no campo social (CHARTIER, 1990; LOURO, 2007). A partir desse conceito, este trabalho investiga as representações sobre a mulher na literatura. As obras selecionadas contribuem para compor um panorama das produções simbólicas a respeito da mulher, bem como, vislumbrar as relações de gênero que permeiam essas narrativas. $O$ lócus da pesquisa são duas obras produzidas em contextos históricos e sociais bem distintos: a "Megera Domada" (1623), obra do século XVII, escrita Pelo inglês William Shakespeare; e "Senhora" (1875), escrita por José de Alencar, no século XIX. As obras foram selecionadas de uma lista de paradidáticos destinados aos alunos do 8 ㅇ ano e 9을 ano do Ensino Fundamental de escolas particulares de Teresina (PI). Esta pesquisa, de caráter documental, adotou como instrumento de análise, os pressupostos teóricos da Teoria das Representações Sociais (MOSCOVICI, 2003) e das Teorias de Gênero (BEAUVOIR, 1980; PATEMAN, 2009). Discute-se como a análise do protagonismo feminino em "Megera Domada" (1623) e "Senhora" (1875) torna-se um importante recurso para problematizar os conceitos disseminados pela Literatura situada em contextos históricos bem demarcados. Considera-se, a partir deste estudo, que "Megera Domada" e "Senhora" se constituem, também, em recursos pedagógicos, que organizam e disseminam modelos sobre o feminino, em épocas e países distintos, em que as mulheres não eram consideradas sujeitos políticos, dotados de autonomia.

Palavras-chave: Literatura. Gênero. Estereótipos. Paradidáticos. Escola.

\footnotetext{
1 Trabalho apresentado no Congresso Brasileiro Ciência e Sociedade (CBCS 2019), promovido pelo Centro Universitário Santo Agostinho, de 03 a 05 de outubro de 2019, em Teresina-PI.

2 Professora orientadora do trabalho. Mestre em Antropologia e arqueologia (UFPI), Professora do Programa Institucional de Bolsas Iniciação Cientifica (PIBIC) do Centro Universitário Santo Agostinho (UNIFSA). Pesquisadora do SEXGEN - Grupo de Pesquisa Sexualidade, Corpo e Gênero (UFPA-CNPQ), e do ComGenero - Comunicação, Gênero, Corpo e Sexualidade (UESPI). E-mail: kelmagallas@outlook.com.

${ }^{3}$ Graduanda no curso de bacharelado em Psicologia pelo Centro Universitário Santo Agostinho (UNIFSA). E-mail: samara.250@hotmail.com.

${ }^{4}$ Graduanda no curso de bacharelado em Psicologia pelo Centro Universitário Santo Agostinho (UNIFSA). E-mail:
} campelogabryelly@gmail.com. 
ANAIS CBCS 2019 | 3 a 5 de outubro de 2019 | Centro Universitário Santo Agostinho - Teresina - PI

\section{INTRODUÇÃO}

A literatura como qualquer outro produto da cultura, está amalgamada a inúmeros elementos ideológicos e visões de mundo que orientam a forma como a realidade, em todo o seu conjunto simbólico, deve ser interpretada (FARIAS; RUBIO, 2012). Como consequência disto, nos contextos escolares, "os livros de textos utilizados pelos professores retratam, em geral, modelos de papeis sexuais tradicionais" (MELLO, 1975, p.142). O livro é um objeto da cultura, e conforme defende Chartier (1990), estão em suas páginas um modo de pensar a realidade social, em determinado momento e lugar histórico. E, como dispositivo da cultura, o livro implica em duas instâncias: uma, que se configura como uma demarcação intelectual, um registro de visões de mundo; e outra, que exprimem "a maneira pela qual uma comunidade produz sentido, vive e pensa sua relação com o mundo (CHARTIER, 1999, p.8). Assim entendendo, os livros paradidáticos não apenas reforçam o sistema de valores e as crenças estabelecidas no campo social, mas atuam, eles mesmos, como normalizadores de uma determinada visão de mundo. Pois, se "não existe nenhum texto fora do suporte que o dá a ler" (1999), a respeito do livro, quando diz que, também não é possível compreender uma obra literária desconectada de seu suporte, a realidade na qual foi concebida, e que, indiretamente, se "constitui o espaço no qual se constrói o sentido".

As estratégias editoriais, que transformam o texto em livro (com seus sinais distintivos), carregam muito mais do que significados aparentes, mas todo um sistema de significados implícitos, que se disseminam pelas páginas do livro:

os que decorrem do estabelecimento do texto, das estratégias de escrita, das intenções do "autor"; e os dispositivos que resultam da passagem a livro ou a impresso, produzidos pela decisão editorial ou pelo trabalho da oficina, tendo em vista leitores ou leituras que podem não estar de modo nenhum em conformidade com os pretendidos pelo autor (CHARTIER, 1999, p.167).

Um paradidático pode, por meio de suas ilustrações, reificar a imagem da mulher como dona de casa, ou como "mãe", como nas abordagens clássicas, mas, sobretudo, pelo vínculo simbólico que estabelece por meio de seus "sinais textuais". Ou, ainda, como diria Chartier (1990), manejados pelo autor e pelo “'horizonte de expectativas' daqueles a quem se dirige” (CHARTIER, 1990). 


\section{congGESSOCOENCIASSOCIEDADE

ANAIS CBCS 2019 | 3 a 5 de outubro de 2019 | Centro Universitário Santo Agostinho - Teresina - PI

Entendendo que a literatura é potencialmente importante para consolidar visões de mundo, e, especialmente, para disseminar modelos de comportamento (CISNE; BRETTAS, 2009; NASCIMENTO, 2014) em contextos escolares, esta investigação visa identificar, em duas obras da literatura: a "Megera Domada" [The Taming of the Shrew ] (1623), escrita por William Shakespeare, e ambientada na cidade de Pádua, durante o renascimento italiano; e "Senhora" (1875), escrita por José de Alencar, sendo ambientada na cidade do Rio de Janeiro, no final do século XIX, quais as representações sobre a mulher. As obras foram selecionadas de uma lista de paradidáticos destinados aos os do 8ㅇ ano e 9 ano do Ensino Fundamental de escolas de Teresina (PI). Visa-se, sobretudo, analisar, por meio das representações sobre a "mulher", quais as relações de gênero e estereótipos sexuais ou de gênero contextualizados naquelas narrativas, conforme o período considerado. Se, conforme Louro (2007, p.11), "a inscrição de gêneros - feminino ou masculino nos corpos é feita, sempre, no contexto de uma determinada cultura, e, portanto, com as marcas dessa cultura", infere-se, a partir dessa investigação, que "os livros de textos utilizados pelos professores retratam, em geral, modelos de papeis sexuais tradicionais" (MELLO, 1975, p.142). Desta forma, esta pesquisa, por meio da análise dos marcadores sociais da diferença (Gênero, Raça, Idade, Classe Social etc.), pretende discutir as representações sociais do feminino presentes na "Megera Domada" e "Senhora", dois dos paradidáticos adotados pelas escolas de Teresina.

\section{METODOLOGIA}

Esta investigação caracteriza-se como uma pesquisa documental que, conforme indica Ferrari (1982), tem a finalidade de reunir, classificar e analisar documentos, distinguindo-se, portanto, da pesquisa bibliográfica propriamente dita. Os livros desta pesquisa foram selecionados a partir das listas de paradidáticos adotados por escolas particulares de Teresina (PI), sendo direcionados para alunos do 8ㅇ ano (12/13 anos) e do 9 ano (14 a 15 anos) do Ensino Fundamental. Os paradidáticos foram lidos, classificados e analisados a partir de categorias, a partir das reflexões de Serge Moscovici (2003), sobre as Representações Sociais. 


\section{REPRESENTAÇÕES DO FEMININO OBJETIFICADO EM “MEGERA DOMADA" E "SENHORA”}

As representações sociais se desenvolvem através de um conjunto de ideias que estão presentes na vida social cotidiana, elaboradas em meio às interações entre os sujeitos, decorrendo daí, determinadas concepções, como as do senso comum e os conhecimentos práticos (MOSCOVICI, 2003). Moscovici estava preocupado em compreender como o conhecimento é produzido e, sobretudo, e quais os impactos que essas formas de conhecimento têm sobre a realidade e às práticas sociais. Moscovici definia as representações sociais como fenômenos sociais, concepções que, depois de elaboradas, conseguem circular na sociedade e se cristalizar, intensivamente, por meio de palavras e gestos, expressões presentes no cotidiano de uma sociedade. As representações estariam presentes na maioria das relações estabelecidas, bem como nos objetos que produzimos ou consumimos, nas comunicações que estabelecemos. Estariam presentes, assim, na literatura, nas narrativas que elaboramos. A literatura é vista neste trabalho como o resultado dessas elaborações, presentes tanto na superfície da página, no texto, como bem abaixo da superfície do texto, nos sentidos que carrega.

Para Moscovici (2010), a finalidade de todas as representações é tornar familiar algo que não é familiar e isso significa que o indivíduo precisa conhecer o objeto ou sujeito para representar. E isso ocorre por meio de dois processos que geram as representações sociais. O primeiro processo é o de ancoragem que "classifica" e dá nome a alguma coisa. Logo, as representações atuariam no processo de categorização, tornando algo considerado "estranho", reconhecível aos sujeitos, reforçando assim, em grande parte, os estereótipos. Os estereótipos são formas simplificadas de compreender os sujeitos, reforçando, como em uma caricatura, quais as suas idiossincrasias, os seus modos de ser. E isso, com frequência, estão presentes na literatura em personagens que, na realidade, apenas encenam estereótipos. Porém, mesmo o estereotipo deixa escapar o que as pessoas, em uma determinada época histórica bem demarcada social e culturalmente, realmente pensam sobre as coisas. Assim, em um contexto social e histórico muito específico, a estereotipia pode reafirmar as expectativas sobre os gêneros, por exemplo, reforçando um "lugar" a ser ocupado socialmente, por homens e mulheres. Esse fenômeno é perceptível em obras como a "Megera Domada" (1623), de Shakespeare, e de "Senhora", de José de Alencar (1875), ambientadas em 
ANAIS CBCS 2019 | 3 a 5 de outubro de 2019 | Centro Universitário Santo Agostinho - Teresina - PI

contextos históricos em que a mulher estava presa aos papeis sexuais e sociais, e ainda não gozava de direitos políticos.

Outro processo, associado a estereotipia é a Objetivação. Esse processo se caracteriza por um conhecimento que transforma algo abstrato em algo quase concreto (MOSCOVICl, 2010). $\mathrm{Na}$ Objetivação ocorre o encaixe de conceitos fixos (e naturalizados) que são associados às coisas objetivas da realidade, como, por exemplo, as concepções sobre os gêneros, e conceitos como a "feminilidade", que é associada à mulher, e a "masculinidade", que é associada ao homem. Essas concepções, resultantes das estratificações de gênero, que são socialmente hierarquizadas, resultam das identidades sociais. Muitos paradidáticos (narrativas de diferentes épocas e contextos sociais e culturais) reforçam estereótipos sobre sexo, gênero, raça, classe social, e precisam ser lidos com essa perspectiva crítica. A concepção de protagonistas femininas sempre belas, frágeis e passíveis, como eram caracterizadas nos chamados "contos de fadas", revelam uma concepção tácita sobre o que é ser e quais as expectativas que estavam sobre a mulher. A objetificação através da forma feminina, descrita, geralmente, por meio de seus atributos físicos, revela uma faceta da objetificação feminina: seus cabelos, corpo, pose, vestuário, toque, movimento corporal e modo de falar, reforçando o seu caráter (da mulher) como objeto do desejo sexual (RIBEIRO, 2005). O sentido dessa objetificação, toda a evocação que se faz do corpo feminino (jovem, magro, saudável, perfeito), perde-se em algum momento; e frequentemente essa erotização se esvazia: é porque não se fala na própria mulher, considerando-a como sujeito dotado de autonomia, mas como algo que o outro deseja e a quer para si como a uma coisa, um troféu.

Todo enredo literário é carregado de significados que estão em coerência com determinadas visões de mundo, o que influencia diretamente na concepção das personagens masculinas e femininas, do que é ser homem ou mulher. Logo, uma história não é apenas para ser contada ou lida, mas como os significados que implicitamente carrega, suas visões de mundo, suas normas de condutas, suas concepções sobre o certo e o errado, sobre como devem ser nossos "modos de ser" no campo social. A esse respeito, o tem a dizer Catarina, a protagonista de "A Megera Domada", sobre as concepções de como uma mulher deveria ser no Século XVII, ou, ainda, Aurélia, sobre essas concepções no Século XIX? Nesse sentido, com intuito de compreender o plano de fundo a que se desenvolvem as histórias lidas, analisam-se, nesta primeira etapa, os contextos socioculturais das 
ANAIS CBCS 2019 | 3 a 5 de outubro de 2019 | Centro Universitário Santo Agostinho - Teresina - PI

personagens, conforme o período histórico em que as obras foram lançadas. Ao analisarmos as características quanto à posição social das personagens principais de "A Megera Domada" e "Senhora", fica evidente que estão correlacionadas com a imagem da mulher da época acentuada pela inferioridade, baseada no direito natural, em que não se tinha necessidade alguma de conferir à mulher um estatuto político, pois para a ideologia do século XVII até meados do século XIX o homem era a causa final da mulher. Logo, se vê intrínseco nas histórias a necessidade de se expandir a representatividade dessas mulheres dentro de papeis diversos na sociedade.

Para Chartier (1990, 1999), que examina a relação entre as práticas e as representações sociais, a partir da produção literária, afirma que a dominação masculina sobre a mulher, tenderia "a ser inculcada através de uma série de dispositivos (inferioridade jurídica; inculcação escolar dos papéis sexuais e da divisão de tarefas; a exclusão de certas esferas públicas, entre outros) tendentes a garantir que as mulheres consintam nas representações dominantes da diferença entre os sexos" (CHARTIER, 2002, p.151). Para ele, as representações que os indivíduos e os grupos fornecem por meio de suas práticas, revelam suas posições nas relações de produção e de poder na realidade social na qual se acham conectados. Percebe-se, assim, por meio do primeiro quadro analítico, que a caracterização da mulher, em cada época, decorre da interpretação política do que é ser mulher. As concepções sobre esse sujeito - destituído ou tendo acesso aos direitos políticos - marcam, por exemplo, as concepções das mulheres nas obras de Shakespeare, a "Megera Domada" (1623), e a "Senhora" (1875), de José de Alencar, considerando que nesses séculos XVII e XIX, as mulheres não possuíam ainda a sua autonomia no campo social, sendo submetidas ao poder decisório masculino.

É importante destacar que, até o século XIX, toda a literatura produzida era feita por homens. Então, a mulher descrita nas obras parte de um olhar do outro, homem, dotado de lógica, do privilégio da liberdade, da autonomia política e financeira, negada às mulheres durante vários séculos. A mulher é, portanto, o resultado de uma elaboração de dessubjetivação, assujeitamento e objetivação: torna-se sempre um "objeto" da descrição, da concepção masculina, e não de sua própria elaboração ou reflexão. A literatura, a mitologia, contos, narrativas, refletem os mitos criados pelo orgulho e os desejos dos homens: é através de olhos masculinos que a menina explora o mundo e nele decifra seu destino (BEAUVOIR, 1949). 
ANAIS CBCS 2019 | 3 a 5 de outubro de 2019 | Centro Universitário Santo Agostinho - Teresina - PI

Nesse sentido, tanto as obras de Shakespeare e de José de Alencar trazem elementos interessantes para a discussão das concepções sobre o gênero feminino em períodos históricos onde as mulheres não usufruíam da isonomia de direitos em relação aos homens.

Catarina, a protagonista de a "Megera Domada", comédia escrita por Shakespeare entre 1590 e 1593, é caracterizada como uma mulher difícil, impulsiva e violenta. A descrição evidencia a sua personalidade "muito forte e a língua afiada". Ela dá sinais de que não deseja ser controlada por ninguém, muito menos, pelo pai. Esse é um dos aspectos dessa obra, que trabalha as relações entre homens e mulheres, mas costurada por uma requintada rede de relações de poder e de submissão.

As disputas amorosas, a guerra dos sexos, e o casamento são temas recorrentes em Shakespeare. É o que aproxima a "Megera Domada" de outras peças do autor, como "Much Ado About Nothing" (Muito Barulho por Nada) e "A Midsummer Night's Dream" (Sonho de uma Noite de Verão). Mas, em "Megera Domada", a narrativa concentra-se no que acontece após o casamento, no conflito de um casal que permanece em disputa. A luta pela dominação e por seu troféu, a submissão.

As disputas amorosas marcam o enredo, cujos principais personagens são: Lucêncio, o filho de um rico mercador, e seu empregado Trânio; Petrúquio, um nobre falido; Catarina, considerada a megera da história; e sua irmã, a meiga Bianca, o seu oposto. A trama gira em torno do casamento, mas, sobretudo, nos rituais de conquista. Em "Megera Domada”, a forma como Catarina rejeita os seus pretendentes, é um recurso dramático bem recorrente na literatura; e no teatro, a quebra de expectativas surte um efeito imediato, agitando as plateias. O que está em pauta, na peça de Shakespeare, não é o respeito às decisões de Catarina sobre sua vida (permanecer solteira), mas como os homens podem domar uma mulher insubordinada, que se satisfaz em quebrar os paradigmas, as hierarquias de gênero, as regras sociais que indicavam qual o seu papel, o que estava destinada a fazer.

A história gira em torno do poder decisório que era exclusividade masculina e a necessária submissão feminina, resultantes do casamento. Catarina, porém, não se comportava como as outras mulheres, especialmente, no que dizia respeito às noções de docilidade e feminilidade, atributos atribuídos às mulheres. Já Bianca, a filha mais nova de Batista, é totalmente diferente de Catarina. Bianca é meiga e obediente, atributos que a tornam bastante qualificada para o papel de esposa, e, 
ANAIS CBCS 2019 | 3 a 5 de outubro de 2019 | Centro Universitário Santo Agostinho - Teresina - PI

por isso, segundo o autor, ela possui muitos pretendentes. Bianca evoca os conceitos de "feminilidade", que reúne um conjunto de estereótipos vinculados aos papéis sexuais femininos. Já Catarina, a ênfase é na insubordinação desses mesmos conceitos.

Fica claro, na história de Shakespeare que tanto Catarina como Bianca são "negociadas" por Batista, mas, pelas regras, Catarina, por ser mais velha, teria que casar-se antes, e somente depois, Bianca, então, poderia se casar. Catarina cria obstáculos ao processo, não se deixa convencer sobre as vantagens de estar casada, ou de perder a autonomia e a liberdade, para se sujeitar ao marido: "Eu pergunto, senhor, é seu intuito transformar-me em brinquedo desses pretendentes?" (SHAKESPEARE, [1623], 1998, pág.28-29). Ao usar essa expressão "brinquedo dos pretendentes", Catarina parece estar bem consciente sobre as implicações sociais do casamento. O brinquedo, algo que é concebido para a diversão de outros, seria o sinal de sua objetificação. Ninguém consegue obter Catarina para si. Mas Petrúquio, um nobre falido, mas ambicioso, está determinado a domála: "Eu sou aquele que nasceu para domar-te e transformar a gata selvagem numa gata mansa [...]" (SHAKESPEARE, 1998 - pág. 61). A expressão "gata mansa" traz um conceito simbólico implícito que diz respeito às pretensões de Petrúquio sobre aquele corpo feminino. Domar, nas entrelinhas do texto de Shakespeare, deixava entrever os contornos de um jogo erótico em andamento.

Ao se casar, finalmente, com Petrúquio, Catarina continua resistindo a ele, mantendo-Ihe a distância, mas as situações se tornam cada vez mais duras com Catarina até que ela desiste de se opor, se submete às implicações do casamento. Diante desse final, o leitor mais atento pode se indagar: mas se o maior desejo de Catarina era manter a sonhada solteirice, por que ela teve que se submeter, afinal, a Petrúquio? Por que ela teve que ser domada? O discurso final de Shakespeare, ao final da peça, não deixa dúvidas sobre o que motivou a história e qual a sua mensagem. A peça era uma crítica à ideia de uma mulher autodeterminada e insubmissa, e ao final, o autor aconselharia as mulheres a obedecerem e a valorizarem os seus maridos: "[...] A mulher irritada é uma fonte turva, enlameada, desagradável de aspecto, ausente de beleza. [...]" (SHAKESPEARE, 1998 - pág. 129).

Se, em vez de analisar a obra na perspectiva de Shakespeare, adotássemos o ponto de vista de Catarina, é possível entender os motivos pelos quais a protagonista se recusava a ser gentil ou agradável com seus pretendentes. A sua gentileza seria entendida como convivência, com a 
ANAIS CBCS 2019 | 3 a 5 de outubro de 2019 | Centro Universitário Santo Agostinho - Teresina - PI

aceitação de sua objetificação, como trazia implícito o convite inexorável para o casamento. E recusar a esse papel seria romper com paradigmas considerados naturais, da essência de seu gênero. Era o rompimento da regra de quem domina e de quem é dominado.

Em “Megera”, a acusação que pesa sobre Catarina, é uma forma de censura; um castigo para que Catarina seja, não apenas domada, mas docilizada, implicando em sua total submissão por meio dos dispositivos próprios do casamento. A supressão da liberdade feminina, condicionando sua existência às tarefas domésticas, obrigações sexuais e à maternidade, levaram várias teóricas do feminismo, como Pamela Allen (“Woman Suffrage: Feminism and White Supremacy”, 1974), e Carole Pateman (1993), com a qual este trabalho dialoga teoricamente.

Conectando o casamento aos jogos da esfera econômica, Pateman (1993) sugere que o casamento é uma espécie de "escravidão", uma vez que, em grande parte, sela direitos desiguais entre homens e mulheres. Em muitos casos, o ritual e/ou documento que oficializa a união, é também o mecanismo que determina que o homem terá pleno controle sobre a vida das mulheres. O contrato de casamento, pois, "dá origem a direitos políticos sob a forma de relações de dominação e subordinação" (1993, p. 24-25). Assim,

os maridos podem, portanto, explorar a sexualidade e o trabalho doméstico das esposas, uma vez que estas, ao contraírem o matrimônio, passam a constituir-se em subordinadas civis. E o grande mérito da teoria do contrato ter apresentado, tanto o contrato original, como os contratos reais do cotidiano como exemplificadores e asseguradores da liberdade individual quando, na realidade, nesta teoria, a liberdade universal é "sempre uma hipótese, uma história, uma ficção política" (PATEMAN, 1993, p.24-25).

Muitos contos de fadas e romances da era moderna celebram o casamento como "o final feliz", e como o único final de estória possível para uma história de amor. Estas concepções são radicalmente diferentes das concepções que afirmam ser o casamento o "contrato civil de escravidão" (PATEMAN, 1993, p. 33). Porém, em contos de fadas e nas estórias românticas da modernidade, a objetificação feminina era, não apenas celebrada como o ideal de mulher; a submissão e a passividade eram ensinadas e cultivadas como características do ser feminino (BARBIERI, 1996), não apenas nas escolas, nas igrejas, mas especialmente, nas publicações destinadas às mulheres. 
ANAIS CBCS 2019 | 3 a 5 de outubro de 2019 | Centro Universitário Santo Agostinho - Teresina - PI

A construção da identidade feminina na narrativa Senhora, reflete de que forma esta identidade pode contribuir para a construção de estereótipos de feminilidade, na medida em que a heroína deposita toda a sua esperança de felicidade na união com o homem que ama. Este comportamento, visível nas narrativas românticas faz indagar o papel dessas narrativas na construção de uma identidade feminina fundada no homem e nos ideais de amor e casamento (CULLER, 1999, p.107-117).

Na obra "Senhora", vale lembrar o contexto histórico em a obra foi publicada, o Brasil do Século XIX, em uma época em que o casamento era regra (e não exceção), e as moças eram ensinadas a procurar um "bom marido" e os homens, evidentemente, a procurarem "boas moças" para casar. A correlação de valores entre o que é considerado "bom" para cada gênero era bem significativo. Para as moças, um homem "bom para casar-se", implicava em ter boa situação financeira para assumir o papel de provedor da casa. Isso decorria do fato de as mulheres, mesmo as escolarizadas, não terem acesso ao mercado de trabalho, dependendo dos homens para sobreviverem. O casamento como uma justificativa para a ascensão social se tornou uma marca de uma época, cujos reflexos ainda se fazem sentir nas relações entre os sexos contemporaneamente.

Em contextos históricos em que era o homem quem escolhia a mulher, e, não o homem quem era escolhido, é possível fazer uma leitura de a "Senhora" sob o ponto de vista das relações de gênero. Nesta obra de José de Alencar, a "regra" é colocada à prova nesse romance repleto de reviravoltas. A história narra o amor de Aurélia Camargo, filha de uma pobre costureira por Fernando Seixas, que a pretere em favor de uma moça rica, Adelaide Amaral. Passado algum tempo, Aurélia, já órfã, recebe uma grande herança do avô e ascende socialmente, mas, ainda ressentida com o antigo namorado, resolve vingar-se dele. Na época em que se passa o romance, o Segundo reinado, está em vigor o regime de casamento dotal, em que o pai da noiva tem que dar um dote ao pretendente a marido e é assim que Aurélia "compra" o seu marido, Fernando, estabelecendo com ele uma relação tensa e marcada pela troca de ofensas e acusações.

Por vários indicativos, "Senhora" é uma obra clássica do romantismo brasileiro, repleto de esquematismos e debates morais. O que fica evidente é que determinação de Aurélia em humilhar Fernando, com quem se casa num gesto de ressentimento, não são bem vistos pelo autor, nem pelo público que o lia no século XIX. Para o julgamento da época, não era moralmente lícito obter-se a 
ANAIS CBCS 2019 | 3 a 5 de outubro de 2019 | Centro Universitário Santo Agostinho - Teresina - PI

submissão de um homem por meio do casamento. Aurélia estava subvertendo uma ordem que não era só socialmente estabelecida; mas, para muitos, essa era uma ordem do campo da natureza, e estava na essência das relações entre os gêneros. Daí, os romances de época reforçarem as concepções das características inerentes a homens e a mulheres, distintamente: a sedução, por exemplo, seria "a fonte de poder para a natureza feminina e a falta de autodeterminação da mulher é também intrínseca à sua natureza" (GASPARI, 2003, p. 32).

Poderia então se avançar a hipótese da construção da identidade feminina fundada na categoria discursiva do sexo. A construção da ideia de sexo como princípio causal, como o próprio segredo da natureza humana, ajudou a criar a ideia da mulher como um ser cuja plenitude residiria em sua relação com um homem, construindo-se uma identidade nele centrada. A literatura leva o leitor a identificar-se com as personagens, contribuindo, assim, na formação da sua identidade:

Na medida em que a literatura, especialmente a produzida com o advento da modernidade, fez da identidade um tema, as narrativas românticas podem ter reforçado os estereótipos de feminilidade, contribuindo para definir a mulher nos mesmos moldes propostos por outras práticas discursivas: "a literatura é um dos lugares onde [...] a ideia de sexo é construída, onde achamos promovida a ideia de que as identidades mais profundas das pessoas estão ligadas ao tipo de desejo que sentem por um outro ser humano" (CULLER, 1999, p.17).

Em Senhora, temos a oportunidade de observar a afirmação da mulher como o "outro" do homem. A personagem Aurélia, num único movimento, reivindica o amor e renuncia a si mesma, pois, ao eleger o amor como o objeto supremo de sua existência, confunde-se com o próprio destino, admitindo mesmo a ideia de morrer por amor. Além disso, percebe-se que quando a personagem tem posicionamentos que explicitam um poder sobre o homem, remete-se a ela uma vilania, enquanto Fernando Seixas, quem ela paga o dote, passa a ser o herói da história.

\section{CONSIDERAÇÕES FINAIS}

A análise do protagonismo feminino em "Megera Domada" e "Senhora" é um importante recurso para problematizar conceitos disseminados pela literatura situada em contextos históricos bem demarcados. Vivencia-se, mesmo contemporaneamente, o debate sobre a hierarquia entre os 
ANAIS CBCS 2019 | 3 a 5 de outubro de 2019 | Centro Universitário Santo Agostinho - Teresina - PI

gêneros. E apesar das inúmeras desconstruções ocorridas nos últimos séculos para a atualidade, em muitos Paradidáticos (FURLANI, 2005), as mulheres continuam sendo representadas estritamente no ambiente familiar, dedicada às tarefas domésticas (SOARES; BORDINI, 2009; NASCIMENTO; AMORIM, 2015) ou à maternidade (CARVALHO, 2006; ROSEMBERG; MOURA; SILVA, 2009), enquanto homens são representados no trabalho, em atividades intelectuais, ou em funções públicas (MICHEL, 1989; AMARAL, 2004; LOURO, 2008).

Nesse sentido, o sexismo se constituiria em uma resposta a um sistema de crenças, que especifica o que é característico de um e outro sexo e, a partir daí, determina os direitos, os espaços, as atividades e as condutas próprias de cada sexo. A literatura é um espaço generificado, que organiza e dissemina modelos. Em "Megera Domada", do século XVII, e "Senhora", do Século XIX, há uma mulher insubordinada que deve ser domada. Mas há sutis mudanças em relação a esse olhar masculino sobre a autonomia e independência feminina. Shakespeare opta pela ridicularização dessa mulher insubordinada. Há violência simbólica, maus tratos e ofensas; em José de Alencar, a mulher ressentida é criticada, exposta em suas mazelas, no rompimento do contrato social. As concepções sexistas, nesse sentido, as narrativas literárias estudadas carregam inúmeras concepções estereotipadas sobre os gêneros, sobre o que é ser homem e mulher, e quais o papeis que cada um deve representar no campo social.

\section{REFERÊNCIAS}

ALENCAR, José de. "Senhora". In ALENCAR, José de. Obra Completa. 4 ed. Rio de Janeiro: Editora José Aguilar, 1959.

AMARAL, I. C. Representações do feminino e masculino nas estórias infantis. Dissert.(mestr.) Universidade Federal do Paraná. Curitiba, 2004.

BARBIERI, Cibele Prado. A masculina e o feminino: a difícil posição feminina. Cogito, Salvador, v. 1, p. 23-27, 1996 . Disponível em:

<http://pepsic.bvsalud.org/scielo.php?script=sci_arttext\&pid=S151994791996000100005\&lng=pt \&nrm=iso>. acesso em 22. ago. 2019.

BEAUVOIR, Simone. O Segundo sexo - fatos e mitos; tradução de Sérgio Milliet. 4 ed. São Paulo: Difusão Européia do Livro, 1980.

CHARTIER, Roger. Introdução. Por uma sociologia histórica das 
ANAIS CBCS 2019 | 3 a 5 de outubro de 2019 | Centro Universitário Santo Agostinho - Teresina - PI

práticas culturais. In: . A História Cultural entre práticas e representações.

Col. Memória e sociedade. Trad. Maria Manuela Galhardo. Rio de Janeiro: Bertrand Brasil, 1990.

A ordem dos livros: leitores, autores e bibliotecas na Europa entre os séculos XIV e XVIII. Trad. Mary Del Priore. Brasília: EdUnb, 1999.

. O mundo como representação. In: À beira da falésia: a história entre incertezas e inquietude. Trad. Patrícia Chittoni Ramos. Porto Alegre: Ed. Universidade/UFRGS, 2002

CHOPPIN, Alain. História dos livros e das edições didáticas: sobre o estado da arte. In: Educação e Pesquisa. [online], v. 30, n. 3, pp. 549-566. São Paulo, 2004.

CULLER, Jonathan. Teoria literária: uma introdução. Trad. Sandra Vasconcelos. São Paulo: Beca Produções Culturais, 1999.

GASPARI, Leni Trentim. Educação e Memória: Imagens Femininas nas "Gêmeas do Iguaçú" nos anos 40 e 50. (Dissertação de Mestrado em Educação). Universidade Estadual de Ponta Grossa, 2003.

MOSCOVICl, Serge. Representações sociais: investigações em psicologia social. Rio de Janeiro, Vozes, 2003. 404 páginas (trad. Pedrinho A. Guareschi, a partir do original em língua inglesa Social representations: explorations in social psychology [Gerard Duveen (ed.), Nova York, Polity Press/BlackwellPublishers, 2000]).

FARIAS, Francy Rennia Aguiar; RUBIO, Juliana de Alcântara Silveira. de Literatura Infantil: A Contribuição dos Contos de Fadas para a Construção do Imaginário Infantil. Revista Eletrônica Saberes da Educação - Volume 3 - no 1- 2012.

FURLANI, Jimena. O bicho vai pegar! - um olhar pós-estruturalista à educação sexual a partir de livros paradidáticos infantis. Tese (Doutorado) - Programa de Pós-Graduação em Educação, Universidade Federal do Rio Grande do Sul, Porto Alegre, 2005.

MELLO, G. N. Os Estereótipos sexuais na escola. Cadernos de Pesquisa, n.15, p.141-144, dez.1975.

MICHEL, Andree. Não aos estereótipos: vencer o sexismo nos livros para crianças e nos manuais escolares. São Paulo: Conselho Estadual da Condição Feminina, UNESCO, 1989.

MOSCOVICl, Serge. Representações Sociais: Investigações em Psicologia Social. editado em inglês por Gerard Duveen; traduzido do inglês por Pedrinho A. Guareschi. 7. ed. Petrópolis, RJ: Vozes, 2010.

NASCIMENTO, B.B. AMORIM, R.S.R.V. Educação Sexista: Uma reprodução da ideologia patriarcal. In: Congresso Nacional de Educação, II, 2015, Campina Grande/PB. Anais eletrônicos... Campina Grande: Centro Multidisciplinar de Estudos e Pesquisas (CEMEP). Disponível em: 


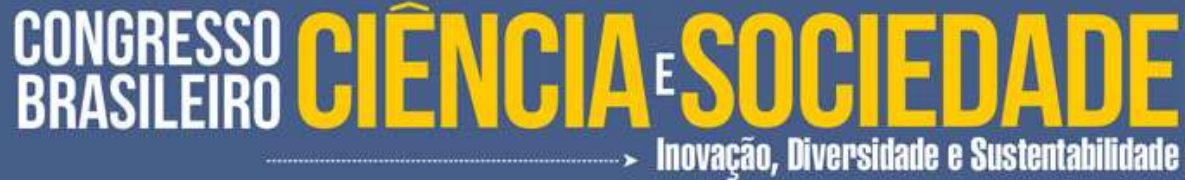

ANAIS CBCS 2019 | 3 a 5 de outubro de 2019 | Centro Universitário Santo Agostinho - Teresina - PI

http://docplayer.com.br/33058729-Educacao-sexista-uma-reproducao-da-ideologiapatriarcal.html. Acesso em 26.ago.2019

NASCIMENTO, B.B. AMORIM, R.S.R.V. Sexismo e educação: produção teórica. In: Forúm Internacional de Pedagogia, VIII, 2016, Imperatriz/MA. Disponível em:<https://editorarealize.com.br/revistas/fiped/trabalhos/TRABALHO_EV057_MD1_SA7_ID1764 _30092016225652.pdf>. Acesso em: 14 fev 2019.

PATEMAN, Carole. "Soberania individual e propriedade na pessoa: democratização e um conto de dois conceitos". Revista Brasileira de Ciência Política, 1: 171-218, 2009.

ROSEMBERG, F; MOURA, N. C; SILVA, P. V. B; Combate ao sexismo em livros didáticos: construção da agenda e sua crítica. Cadernos de Pesquisa. V.39. № 137. P.489 - 519, Mai - Ago, 2009.

SHAKESPEARE, William. A Megera Domada [The Taming of the Shrew]. Tradução de FERNANDES, Millôr. L\&M Pocket, 1998.

SOARES, Edimara; BORDINI, Santina. Livros didáticos de ciências e a fabricação das identidades de gênero, sexualidade e etnia. III Simpósio Internacional e IV Fórum Nacional de Educação Políticas Públicas, Gestão da educação, Formação e Atuação do Educador. Universidade Luterana do Brasil, Torres, Anais. 2008. 